RUNNING HEAD: Mediation strategies in the face of custody conflicts

\title{
Mediation strategies in the face of custody conflicts
}

Wenke Gulbrandsen, Hanne Haavind, and Odd Arne Tjersland

Abstract

Systematic analyses of initiatives and responses from mediators working with parents in intense conflicts about child custody and care brought forward variations in effective strategies. The findings are presented along six dimensions: The topics that were addressed, how the agenda for the sessions was decided, focus on agreement vs relational topics, oral vs written orientation, limited vs generous time, and parental vs system focus. Effective mediators handled these dimensions with flexibility, recognized and validated both parents' perspectives, accepted and explored differences, differentiated topics, focused on relational issues when needed, tracked the process by written summaries, and encouraged testing solutions.

\section{Introduction}

How may mediators proceed when parents expose intense conflicts about child custody and care? To discover more about how mediators are able to navigate during sessions with parents who arrive in mediation with a low level of hope and a high level of conflict, we have analyzed the interactions during mediation sessions in a set of selected cases from Norway ${ }^{1}$.

\footnotetext{
1 This is the third internationally published article based on data from the FORM project (in Norwegian, abbreviation for "parents in mediation"). The article is an empirical study of mediation sessions with 154 couples and a follow up 18 months later
} 
RUNNING HEAD: Mediation strategies in the face of custody conflicts

By Norwegian law, mediation is a mandatory part of the process of separation or divorce for all couples with children. Some of the parents who arrive for mediation under these premises already agree on a conjoint arrangement, and others expose intense conflicts about child custody and care. In a naturalistic study of the sessions in a selected set of high-conflict cases, we started out with two main objectives. The first objective is to describe what actually characterized conflicts in mediation with divorcing parents when such conflicts escalated and were left unsolved (Gulbrandsen, Haavind, \& Tjersland, 2018). The second, as is the aim of this article, was to describe the mediators' strategies when faced with these conflicts and how they were able to replace the often deadlocked dialogues with more explorative procedures that could lead to agreements.

The focus is thus on the present mediation practice within Family Counseling Services centers in Norway and the conversations between the mediator and the couple. Before we describe the study and the results, we will summarize some ideas, theories and perspectives that have been central in the development of the field of mediation internationally, as well as laying the grounds for the Norwegian legal arrangements regarding mediation.

\section{Mediation as an intervention for divorcing or separating parents}

Two pioneers within the field, Coogler (1978) and Haynes (1981), were the first to raise the issue of mediation as an alternative to juridical settlements between separating parents. The idea was to help the parents find their own solutions for care arrangements and

(Tjersland, Gulbrandsen \& Haavind, 2015; Gulbrandsen, Haavind, \& Tjersland, 2018). Earlier on, parts of the findings were published in Norwegian in Tidsskrift for Norsk Psykologforening. 
RUNNING HEAD: Mediation strategies in the face of custody conflicts

cooperation after a break-up. Coogler and Hayes both described structured methods for finding specific arrangements with regard to the provision for and daily care of children. As the idea developed, other voices raised the issue of emotional and relational conflicts between parents. The concern was that mediation should offer help to parents in addressing such issues as well, as a means to facilitate the process of agreeing on care arrangements. Thus, ideas from various therapeutic traditions came to inspire the field of mediation (Brown 1997; Bush \& Folger 1994; Emery 2012; Irving \& Benjamin 2002; Kruk 1997; Lang \& Taylor 2000; Tjersland 1998; Walker, McCarthy, \& Timms 1994; Winslade \& Monk 2001). After reviewing these developments, we have formulated a broad definition of the mediation process that can encompass much of the current diversity in the field:

Mediation is a cooperative process between separating or separated parents, assisted by a mediator who strives for impartiality, and where all decisions ultimately lie with the parents. The intention is in part to address issues that occupy parents and children about their future as a family, and in part to find solutions that can be agreed upon. These solutions can be cooperation arrangements regarding the children or other issues. The overarching task for the mediator is to keep a focus on reaching an agreement, while at the same time making use of relevant interventions to facilitate the process of dialogue between the parents. (Gulbrandsen \& Tjersland, 2010, p. 697)

With the exception of the transformative tradition (Bush \& Folger 1994), which has questioned the focus on the agreements, this definition seems to have a broad consensus behind it. Nevertheless, many questions remain unanswered. One of them regards what "relevant facilitating interventions" might involve. Few observational studies of direct mediation practice exist, which might explain why the interventions have often been described in terms that seem generic or unspecific. 
RUNNING HEAD: Mediation strategies in the face of custody conflicts

One of the issues raised in this discussion is the differentiation between a focus on emotional processes versus on agreements. This distinction can be considered artificial, as both making and settling on an agreement are processes affected by emotions. Nevertheless, in the context of mediation, it can contribute to a clearer dialogue if the mediator manages to sort out the emotional reactions from the actual topics on which to decide. Although several of the mediators mentioned above have highlighted the importance of making space for emotions and relational questions, there have been different ideas about the purpose of this space. Some have referred to the usefulness of "venting" emotions. Others have focused on the specific emotions being expressed (anger, despair, sorrow, etc.) and how to regulate them. However, the purposes mostly underlined have been to help the parties talk about their emotional reactions, obtain a clearer meaning of what they might express, and explore if and in what way such reactions may inhibit the parents in the process of finding solutions (Emery \& Sbarra 2006; Poitras \& Raines 2013; Saposnec 2004). A recent interview study about how mediatiors handled tensions between themselves and the clients discuss topics close to those we will address here (Baitar, Mol, \& Rober 2016).

In a previous article, we have identified and described eight sources of conflict between separating parents experiencing a high level of conflict (Gulbrandsen, Haavind, \& Tjersland 2018). Two were related to the break up: reluctance by one of the partners to accept it and/or grievances regarding how it happened. Four were about concerns over the partner's lack of ability and responsibility as a caretaker due to their own problems, lack of understanding of children's reactions, inability to listen to children who had become actors in the conflict, and/or failing to provide for the children. Other sources of conflict could include parents with irreconcilable plans for the future and situations where voices from outside the mediation room interfered with the process. Delineating sources of conflict in this way can 
RUNNING HEAD: Mediation strategies in the face of custody conflicts

enable the mediator to verbalize and explore them, thus helping the couple cope with rather than suppress or ignore the emotional reactions they evoke.

With these sources of conflict as a point of departure, we have analyzed the same material looking for strategies that mediators might use when faced with these grievances, concerns for the children, etc. The main objective has been to identify strategies that seem constructive in the face of deadlocked conflict.

\section{Context: mandatory mediation}

Upon revising the Act on Marriage in 1991, the Norwegian Parliament made mediation mandatory for divorcing parents with children below the age of 16 years. The intention was to prevent and reduce problems by offering parents assistance in arriving at a written agreement regarding shared care arrangements for their children. To begin with, it applied to parents who had been married or who were intending to take their conflict to court. It was later expanded to apply to all cohabiting parents splitting up. One session is mandatory, but each couple is offered up to seven sessions. The mediation is given at local Family Counseling Services centers and is free of charge. The sessions are led by educated mediators, including psychologists, social workers, and a few lawyers.

This mediation process, although mandatory, is not court-based. Couples receive a mediation certificate after attending one session. This certificate enables them to seek formal separation, apply for economic support by social services and bring the case to court if they wish. As such, the Norwegian arrangement deviates from the definition of mediation given above, in that many of the parents are not seeking help on their own initiative. Further, the mediator's role is regulated by several guidelines regarding how to summon the parents to 
RUNNING HEAD: Mediation strategies in the face of custody conflicts

mediation, what information to give, etc. Importantly, the mediator has a mandate to "protect the children's interests". These regulations can impose challenging constraints on the mediator's task of establishing a good working alliance with the parents. Several examples of such situations will follow, showing how the mediators can perform their role to help parents within this framework of mandatory mediation. The strategies identified here should also be useful for other mediation work with parents voluntarily seeking help.

\section{Methods}

\section{$\underline{\text { Design and procedures }}$}

To create a sample of high-conflict cases, we recruited 154 couples who were going through a break up and therefore were attending mandatory mediation. The recruitment was conducted through four Family Counseling Services offices and one external mediator over a four-year period. Altogether, there were 12 mediators, most of whom had several years of experience, who led the mediations and at the same time gathered data. When the parents agreed to participate in the study, they also stated their willingness to have sessions audiorecorded. The mediators were instructed to perform the mediation practice as usual. Based on demographics such as age, number of children and years of education, this sample is representative of separating parents seeking mediation in Norway (Tjersland, Gulbrandsen, \& Haavind 2015). The level of conflict among these couples varied significantly.

Each parent filled out a self-report form regarding their background, their perceived level of agreement with their ex-partner and their hopes of finding a solution in mediation. They were also asked to give a short assessment of each session. The mediator performed the same assessment, describing potential challenges in the work and reporting on the outcome of 
RUNNING HEAD: Mediation strategies in the face of custody conflicts

the mediation. At an 18-month follow up, each parent went through a telephone interview regarding the mediation, the current cooperation between the parents and the background for the break up.

\section{$\underline{\text { Sample }}$}

The identification of high-conflict couples (HCL) was based on two sources: Upon the first arrival, one or both parents reported great differences of opinion about solutions concerning children and/or economics ( 3 or less on a scale from 0 (totally disagree) to 7 (totally agree)), and the mediator assessed the mediation work as very challenging after the first session (3 or less on a scale from 0 (very difficult) to 7 (easy)).

This procedure identified 38 HCL couples. These couples did not differ from the other 116 couples in terms of demographic measures such as age, years of education and profession. However, they were more likely to be in the process of taking their conflict to court (HCL 58\% vs others 11\%) and reported having little hope for the mediation process (HCL 53\% vs others 7\%). Very few of the HCL couples made use of more than one or two mediation sessions. Moreover, only 29\% in the HCL group reached a satisfying agreement, compared to $80 \%$ among the others (anonymous reference).

\section{$\underline{\text { Data }}$}

The 38 HCL couples had met for a total of 98 sessions varying from one to seven sessions. In order to get manageable transcribed raw data for analyses we had to select cases. To get a representative variety of cases we based the selection on factors such as number of sessions, number and age of children, type of mediation and outcome. This gave us $28 \mathrm{HCL}$ couples with 60 sessions that were transcribed by the authors and by research assistants working on related research questions. For each transcribed session, a written summary was 
RUNNING HEAD: Mediation strategies in the face of custody conflicts

made containing descriptions of topics, the parents' communication styles, and examples of the mediator's responses.

For the present study, we purposefully selected 16 HCL cases, with 46 sessions. We made sure to include both married and cohabiting parents, cases with one, a few and several sessions, and couples with or without the intention of bringing their conflict to court. Ten out of 13 mediators represented in the whole material were included. This sample was characterized by variation and contrasts both in terms of areas of conflict covered and mediation approaches. The results presented below are based on inductive an inductive analyses of transcribed sessions from this purposive sample (see analysis).

To explore whether our analysis from the above-described sample was saturated and valid, the first and third author independently read the transcriptions from the remaining 12 transcribed HCL cases and listened to the tapes from the last $10 \mathrm{HCL}$ cases. This process added no new dimensions to our analysis, but strengthened and confirmed the observations that we had already made of the characteristic reactions from the parties to the mediation.

\section{$\underline{\text { Analysis }}$}

What we have come to focus on and understand through this analysis is inevitably affected by our long-standing experience as mediators and by our larger view of theories and research within the field of mediation (anonymous reference). Some areas have been of particular interest to us: how sources of conflict and emotional reactions are met with in mediation, how the mediator frames the sessions, what other interventions he or she uses and how these processes can be understood from a holistic perspective. 
RUNNING HEAD: Mediation strategies in the face of custody conflicts

This consciousness about the preconceptions we bring to the analysis is inspired by a social constructionist understanding of Grounded Theory (Charmaz 2008). The method is exploratory and inductive, thus enabling the generation of new, rich insights about a phenomenon, while allowing for the inherent influence of the questions and perspectives that the researchers carry with them. The first author read through the 16 selected cases and coded any statement from the mediator. These statements were sorted into two broad categories: initiatives, when the mediator introduced a new topic by a statement or by a question, and responses, when the mediator's statement was a response or reaction to something in the dialogue between the parents. This sorting left us with ample examples from both categories, material that the three authors studied and discussed. The diversity of the categories of initiatives and responses were striking. In describing this variation, we found that some of the variants seemed to constitute a dichotomy, or extreme oppositions on various dimensions. A major portion of the statements coded as responses could also be understood as initiatives along one of these dimensions or on new dimensions that appeared through the process.

The result of this phase of analysis was six dichotomies describing opposite points on a dimension representing where the mediator focused the attention in the face of conflict. These dimensions or dichotomies can illustrate the range of interventions a mediator often has at hand within the framework of mandatory mediation in Norway. In the following, we will describe and exemplify these six dimensions:

- Focus on formal requirements vs focus on the parents' agenda for mediation

- The mediator defines the topic vs the parents define the topic

- Focus on the agreement to be reached vs focus on emotions and relationship

- Oral vs written orientation

- Limited time vs generous time

- Focus on the parents alone vs focus on the system they are part of 
RUNNING HEAD: Mediation strategies in the face of custody conflicts

A further step in the analysis was to study how the parents responded to the interventions within each dimension, both immediately and later on in the sessions. Did they follow, avoid, protest, listen to each other, start a quarrel or confirm the input coming from the mediator? We went back in our notes to examine the responses, first among the 16 cases, second among the 12 cases and third among the 10 cases we had on tape.

\section{Results - different dimensions for approaches}

Prior to taking a closer look at these dimensions, we will describe some characteristics of how the 38 cases of high-level conflict developed. These cases all involved high-conflict dialogues, posing several challenges for the mediator. This challenge is evident in the outcome: $71 \%$ did not reach an agreement. The transcripts also strongly reflected this. Typically, through many of the mediation processes, the antagonisms between the parents increased and the dialogue deadlocked - with the mediator sometimes being a part of this conflict. The mediation in these cases was terminated after one or two sessions, often in a tone of resignation and exhaustion.

This kind of repetitious intensity often characterized processes where the mediator chose strategies placing focus to the left of the abovementioned dimensions. In some cases, it seemed as if the mediator moved further to the left as the conflict escalated - i.e., focusing more on formalities and topics defined by the mediator, pushing towards agreement, as though limited time should accomplish the task - while the idea of written summaries was completely avoided.

When the mediator chose interventions placing focus further towards the opposite side of these dimensions, the dialogues more often seemed to continue. In spite of disagreements, 
RUNNING HEAD: Mediation strategies in the face of custody conflicts

the parents listened more to each other and returned to further sessions. Although some of them did not reach a complete agreement, they often came to agree on some central points. Others reached agreements that seemed to resonate well with both parties (29\% of the HCL group).

\section{$\underline{\text { Focus on formal requirements vs focus on the parents' agenda for mediation }}$}

How the mediator introduced the first session varied. In some cases, she immediately focused on the legal framework of mediation and on the mediator's role. A significant portion of time would be used for this:

T: You have seven mediation sessions at your disposal, of which only one - the one we're in now - is mandatory. So I'll write you a certificate of mediation before you leave today in any case.

$M: M h m$

T: The purpose of this mediation is to arrive at a written agreement regarding care arrangements for your children. There are three points you must agree on.

M: Yeah, we both have the (refers to information leaflet they have been sent in advance)

T: Yes. But you see here that these are about your responsibilities as a parent, living arrangements for the children, and arrangements for how and when the child spends time with each parent. We're going to take a closer look at what this means, but what is desirable is that you make a written agreement on this, and the objective is to make it as predictable as possible for the children and yourselves and prevent conflict between you as parents. It is voluntary whether or not you make this agreement. I have a template that you can use to make this agreement if you wish to. As I've mentioned, it is voluntary after this session. Everything you say here is confidential, and I don't keep any journal from the sessions. 
RUNNING HEAD: Mediation strategies in the face of custody conflicts

This conversation starts with the parents hardly getting a word in. Other introductions with the same focus were more open, sketching out the formalities and allowing for dialogue after less time. The message was always the same: the offer of seven sessions, the first one being mandatory and resulting in a written confirmation, and the objective being a formal agreement on shared custody and living and contact arrangements regarding the children. Furthermore, some mediators underlined that the process was confidential as long as there were no severe concerns about custody for the children.

The mediators on the other end of this dimension clearly downplayed the attention to these kind of formalities. Rather, they emphasized their role as a helper and inquired into what the parents wished to discuss.

T: The objective of mediation, as I'm sure you know, is for me to try to help you, in your situation, see if there is any way that I can contribute, to help you as mom and dad for your boys...(to father): You made this appointment?

Father: That's right.

T (to mother): So is it all right with you that I start with him?

Mother: Sure

T: It is. So I'll check with you (looking at the father); in what way can I be of help for you?

The differences in approach are remarkable, as are the differences in the parents' responses. In the first example, the parents respond with reservation, watchfulness and sometimes impatience: "Yeah, we know that". They could also respond somewhat defensively to the mediators' emphasis on the child's best interest: "Yes, that is why we're here". Such responses have the hallmark of someone who feels as if he or she is being called in to a kind 
RUNNING HEAD: Mediation strategies in the face of custody conflicts

of quality control, where the 'State' defines the standards, and the mediator is there to ensure that these standards are being reached.

Mediators on the other end of this dimension opened the dialogue by focusing the attention on the parents and how they wished to use the time at their disposal. In the example above, we also see that the mediator asked each parent individually and not the parents as a unit. This approach has been emphasized as useful in mediation literature (Slaikeu 1996). Parents in conflict or disagreement do not necessarily feel like a "we". When asking them questions as a unit, the mediator risks imposing on them a false sense of togetherness or reconciliation for which they are not yet ready. Further, the mediator in the example above asks permission to approach the parents in a specific way: to ask the one who has made the appointment first. An alternative approach is to ask the parent who did not make the appointment first about what he or she thinks the other parent wants help with. The follow up is to ask the other parent the same question, thus helping the parents consider each other's perspectives. This approach is a way to signal that the mediator is concerned with the parents' relationship and how they understand each other.

The mediator defines the topic vs the parents define the topic

More often than not, the mediators who chose to open the conversation with a focus on formal requirements continued by pointing out the topics that were to be addressed in mediation, including living arrangements, shared responsibilities and plans for contact with both parents.

T: Yes. So if you start on the first point of these three questions that are part of this. As of today, you have shared custody for your son. Do you wish to continue with that? Father: I want that 
RUNNING HEAD: Mediation strategies in the face of custody conflicts

\section{T: Do you know what shared custody is?}

Father: Yes, isn't that.... what do you mean?

This hesitating and awaiting attitude in the parents returned the emphasis to the moderator, who found herself in a position of providing further information. In this case, as in many others, the mediator continued by explaining the relevant terms thoroughly and in detail. The intention was obviously to provide clarity to the conversation and to give the parents an overview of the legal concepts before making a choice. Although the parents appeared to listen, the message did not seem to reach them. They responded with silence or brevity and adapted to the formal tone of the conversation. Their responses were sometimes tainted with a hint of impatience, as in "yes, living arrangements are exactly the point we disagree on" or "yes, we know that". This kind of dynamic would sometimes develop into a brief session where the mediator did most of the talking, where everybody agreed that they disagreed and where no light was shed on any of the sources of these disagreements.

On the other side of this dimension, we find mediators who leave the task of setting the agenda to the parents. They start by asking each parent about how they can help. Open questions such as "how can I be of assistance", "what is most important to you to address" and "what do you need to address in this current situation" were frequently used. The mediator would listen and take notes. She would then feed this information back to the parents, having tried to sort out some main topics, rephrasing "demands" to "desires". This approach could involve using a flip-chart. This process allowed for exploring each parent's concerns and wishes from his or her own perspective.

A challenge in this work was when the parents disagreed on what topics to address.

The mediator often tried to avoid limiting the scope of what could be addressed. Some topics revolved around living arrangements, holidays, grandparent involvement, new partners, and 
RUNNING HEAD: Mediation strategies in the face of custody conflicts

so on. Other topics were of a more relational character, often involving more intense emotions, for instance, causes of the break up and what to tell the children.

Another challenge was when one parent gave an answer that pointed to topics that indirectly had a contradictory meaning:

\section{T: So I ask you again, Dad: What do you think Mom wants to address?}

Father: She can answer that one herself! This is a clear-cut case. I have him (the son) every other weekend and wish to see him one extra day a week. Two weeks between every time I see him is very long...A few weeks ago I was invited home to have dinner and discuss holiday plans. All of a sudden, she tells me how nice it was to have me over and what a shame it was that it ended up as it did.

Which of these messages should the mediator reply to? Should she address the topic he explicitly raised - extending the time for visitation - or the topic that could be read between the lines, a question of reconciliation? There is no simple answer to this question. One alternative is pointing to the sentiment: "the way you experienced it, she left you". Another is addressing the potential intention: "what about the contact between you as parents - would you wish to address that?" Quite frequently, the parents would reject such mediatorinitiated topics. There are several potential reasons for this rejection: it could be the way the mediator framed or phrased it, or because she brought it up too soon. There are also examples of good strategic timing in the material, where the mediator mirrored some topics but withheld from addressing others. This timing could stretch over several sessions.

On some occasions, one parent would try to set the agenda by solely addressing his or her chosen topic. When the mediator focused on letting the parents set the agenda, she would not necessarily interrupt this immediately. Rather, she would let them talk before returning to 
RUNNING HEAD: Mediation strategies in the face of custody conflicts

the list of topics the parents were suggesting. From this list, she would ask the parents which topic they wished to address first. This question did not exclude new digressions. When the parents digressed onto a different topic, the mediator would interrupt to check whether that was indeed the topic they wished to start with. If a new topic suddenly were to be brought up during the discussion, for instance, new partners, the mediator would ask whether they wanted that put on the list of topics to be addressed.

In this way, the mediators of this orientation were able to structure the conversation while at the same time leaving the agenda with the parents. The list of the parents' suggested topics gave the mediator a way out of destructive and repetitive dialogues: "Shall we return to the topic of exceptions from the regular arrangements? What did you want the agreement to be here?" The list also provided an opportunity for the mediator to stay on emotionally loaded topics - and to address these emotional tensions when she thought it relevant. This process is described in further detail in the next section.

\section{Focus on the agreement to be reached vs focus on emotions and the relationship}

No mediator in this study placed focus solely on reaching an agreement, but some leaned more towards this than others. These mediators would try to avoid emotionally loaded topics, especially at the start of the sessions. This avoidance could be achieved by metacommenting - "We should focus on the agreement to be reached here" - or by suggesting postponing this topic - "Shall we leave this for now and start with a focus on the agreement?" These strategies were in vain remarkably often in dialogues of high emotional intensity. Even more striking was the parents' response when the mediator tried to subsume or ignore these emotions. The emotional tensions would continue and soon find new and potentially more intense expressions. The result was dialogues characterized by frequent shifts and lack of 
RUNNING HEAD: Mediation strategies in the face of custody conflicts

mutual recognition. More often than not, the conversation was terminated with neither the agreement nor the sources of conflict properly addressed.

Mediators on the other side of this dimension typically dealt with such emotional interruptions as legitimate topics to be addressed, sometimes by adding them to the list of suggested topics, sometimes by allowing the parents to digress into them. The latter approach was often taken when the emotional tensions seemed to hinder further progress in the mediation. The digression would be structured as a loop leading back to the topic of agreement.

On some occasions, the mediator would lead the conversation on to emotionally loaded topics. One example is from a couple with an infant who was still breastfeeding. The father wanted time with his child, and the mother was reluctant, expressing concern and hesitation. The mediator chose to focus on these concerns rather than on the specifics of an agreement on this aspect:

T: Yes, but if we took a moment to think beyond rights. Is there something you could say or do that you think might make Mom more secure in this?

Another example:

T: You want cooperation. Right now, your partner feels insecure about that. Can you accept that we spend some time on this insecurity, so that it does not hinder your cooperation?

Such messages were sometimes effective. However, it was also at times a challenge to make both parents accept this direction. In one example, one parent opens by stating that "I am here to discuss arrangements for shared care, not to reopen the topic of the divorce". The 
RUNNING HEAD: Mediation strategies in the face of custody conflicts

mediator had to take this protest seriously if she wanted the participants' acceptance to address the topic of the break up. One mediator chose this solution:

T: You have decided to leave. Are you ok with us spending some time on addressing the background for this decision? It probably looks very different from your two perspectives, and it can sometimes be useful to get a clearer picture of these differences before we work on reaching an agreement.

Such interventions could enable the mediator to address the sources of the conflict before returning to the discussion about an agreement. This approach created some space between "agreement" and "emotions", where issues could be addressed such as reactions to what the mother-in-law had said to the father, experiences of betrayal connected to the break up, concerns for children who had stomachaches or who were reluctant to return home after having been with one of the parents, and so on. These digressions were often brief, as if one's experiences being heard and validated with a third party present was enough. They could also be more elaborate, focusing on how the parents could relate to the issue to reduce concerns. Most often, such issues were addressed with both parents present. In one case, the mediator had separate sessions with each parent before continuing mediation (Kjøs, Tjersland, \& Roen 2014).

From these examples, the mediation process is clearly oriented towards the right side of the dimension but not exclusively so. Perhaps it is best described as a dialectical process oscillating between topics of agreement and sources of emotional tension. Gradually, the agreement part of the process begins to occupy more space. By allowing time to be used on these concerns and the replies to them, the mediator was able to validate each parent's experience and, with time, to differentiate and sort the different emotions and experiences that 
RUNNING HEAD: Mediation strategies in the face of custody conflicts

had tangled up into an undifferentiated bundle of conflict. Of course, the mediator could be put in the position of being asked to confirm the validity or realism of one parent's concerns. Some mediators received this challenge by validating the experience of concern without assessing the potential "truth" in it, emphasizing that the experience of concern is subjectively true, and in that sense, it is worth addressing.

\section{$\underline{\text { Oral vs written orientation }}$}

The objective of mediation, as it is defined by Norwegian law, is to arrive at a written agreement. The guidelines also emphasize that one should strive for this. The mediators approached this demand very differently. Near the start of the process, some clearly flagged that this was voluntary:

T: I want you to make a written agreement. This is not mandatory; you decide. But it is recommended.

This approach is a sort of double communication, especially when facing parents in conflict. The mediator offers an easy way out of a situation in which it seems impossible to reach a written agreement together. Some of the mediators sought to limit the scope of the proposed written agreement, often narrowed to the three formal points of agreement, and could provide a ready-made form that was convenient to fill in. These mediators minimized the agreement, presenting it as if it was an inconvenient task:

T: Making this agreement is voluntary; I have a template here that you, for example, can use to make this agreement, if you wish to do so.

There were also instances where the mediator led the conversation away from the topic of written agreements. In one example, the father argued for making clearer rules for unexpected changes, as these situations often led to what he labeled "unnecessary conflicts": 
RUNNING HEAD: Mediation strategies in the face of custody conflicts

T: Ok, so on the one hand, what we're talking about, regarding a written agreement, is to have something tangible to work with. The other topic is more a topic of how we work together. Giving each other information, not give the children expectations, right?

Father: Yes.

T: Do you think we should make some written formulations about that as well, or is that something that you have to talk about and agree on how?

Father: Yeah, I feel that it is, like, I don't think it is, it's just about starting to think differently. T: Ok, so it's something you have to talk about, and in this regard it is a topic of oral agreement?

Whether this avoidance was about the mediator's understanding of the guidelines, about pressure on time or a fear of deadlocking the dialogue on details is hard to know. One thing is sure: it did not lead to more clarity in cases like these. This approach is in clear contrast to mediators taking notes as an active strategy in the face of disagreements. These mediators typically wrote down what the parents said, making comments such as "I'll get this down on paper so that I remember for when we're drafting the agreement later". With the parents' permission, she would email them a short memorandum after the session. This memo contained a selective report that could be about the parents' shared intentions and wishes, the topics that had been addressed and the different viewpoints each had on these, points on which they had agreed so far, and further topics to be addressed. The mediator would label the summary "preliminary draft" or "work in progress". The parents were asked to read through it to correct any imprecisions or misunderstandings:

This is a first draft in forming an agreement. Anything can be changed or removed. Agreement for contact with and cooperation around our daughter Lisa: 
RUNNING HEAD: Mediation strategies in the face of custody conflicts

It is important to the both of us that Lisa keeps two parents after we split up and that she gets to spend as much time as possible with both. We'll make it a priority to find places to live within the same uptake area for the school she's starting this autumn.

1. We'll have shared custody for Lisa

(Comment: this involves agreeing on all major decisions for Lisa in the future (you can read more about this in the information leaflets.)

2. As a starting point, we want Lisa to spend roughly half of her time with each parent. One solution is that Mom has her from Monday to Tuesday the following week. Then, Dad takes over and has her until the following Monday. And this continues. The change happens by one parent delivering her to the kindergarten (later school) and the other picking her up.

(Comment: you were in doubt about how predictable this could be. Dad's work means a lot of exceptions. You both emphasized predictability as well as flexibility as important. Mom does not think that it is a good solution for Dad's mother to step in when Dad can't. We'll continue the discussion of this next time. The amount of time the child spends with each parent can influence your right to financial support and the amount you get. See the Social Services webpages for more information.)

3. Residential address for Lisa: not decided

4. Holidays, such as Christmas, Easter and summer: not discussed

5. Exceptions from the regular arrangements: the parents have to ask at least $x$ days in advance if it is ok to deviate from the regular arrangement.

(Comment: Mom wanted notice 14 days ahead, Dad felt that was difficult. Not decided upon.)

Making summaries like these definitively slowed down the process in conflict cases, but it contributed to clarity, provided validation that both parents had been heard and made progress evident. The mediator would sometimes attempt to phrase herself in ways that could 
RUNNING HEAD: Mediation strategies in the face of custody conflicts

contribute to untangling conflicting narratives. The following example is from a couple that had several sessions and experienced a high level of conflict about the care for their 8-yearold son. The mother felt that the father had failed as a father and found it hard to trust his promises of improvement. On one of her notes on process towards the end of the mediation, the mediator wrote this:

Ever since Ole was one year old, Mom has contributed to him keeping in contact with his dad. She wanted Ole to have a close relationship to his dad and they visited him regularly. Mom did this in spite of advice from people around her to cut off contact. Ole thus got to keep both of us as parents. Dad trusts completely Eva's competence as a mother, and Mom thinks Adam is good with Ole. This makes it easier for us to cooperate. Our history as a couple still influences and challenges our cooperation as parents. Clear agreements facilitate our cooperation. Vague agreements can cause Mom to worry a lot about Ole's wellbeing. From now on, Mom will take the responsibility to communicate her concerns when she has them, not later. Dad is ready to listen to such concerns and report to Mom. We will encourage Ole to contact us through email or phone.

Short memos like this cover what was said and agreed upon but also clearly state any differences of opinion between the two parents. An argument against this approach is that it takes the responsibility to form the agreement away from the parents. However, according to the mediators involved, in these cases, the parents typically did not take the opportunity to bring their own drafts. The differences between them seemed too overwhelming to make such efforts. When taking over the role of putting words on paper, it could be time-consuming for the mediator to make the first summary, but in most cases it felt much easier to revise it later on, and it was helpful in keeping track of the process. An issue has been raised against the practice of emailing such memoranda to the parents. Clearly, this practice must be with the 
RUNNING HEAD: Mediation strategies in the face of custody conflicts

parents' previous consent, and the document should always be labeled a "preliminary draft", underlining that it is how the mediator understood them in the last session and that misunderstandings can be corrected the next time. Such an approach seemed to be a very useful in dealing with some of high-conflict cases in this study.

\section{Limited time vs generous time}

In the descriptions of the approaches above, it becomes clear that the mediators on the left side of the dimension often had a focus on time limitations. This focus is clearly seen in how they emphasized in the first session that only one session is mandatory and in how they hurried to narrow focus onto the topics of agreement. The inherent flexibility in having an opportunity for seven sessions was under-communicated. One mediator's opening statements exemplify a different approach:

T: As I'm sure you know; this session is mandatory. You'll get a mediation certificate after this session. You have more time on your hands. To begin with, you can make use of three further sessions. If you approach a solution at that stage, another three are available for you. That is the framework. We've already set up a new session next week, so that you know you can come back soon if you want.

Generosity with time gives parents space to discuss topics that concern them. Furthermore, it gives them time to try out different arrangements. This last point is crucial, because the task of reaching a permanent and lasting agreement within one session is a task that might seem daunting at best to the parents. The opportunity to try out an arrangement without committing to it offers security that might open the parents up to new experiences. In some cases, this approach changed the dialogue from one based on principles to one based on 
RUNNING HEAD: Mediation strategies in the face of custody conflicts

experiences. Some mediators pointed to the value of the work the parents did in sessions from a life-long perspective:

T: This is the progress we made today. This can develop well. I'll be here as long as you need me. It is great that you are both investing time in this now. You're going to be parents together for a long time! You really never stop being a parent.

Focus on the parents vs focus on the system they are part of

The focus on the two parents is inherent in the mediation arrangement. However, recent years have seen great interest in the idea of bringing the children into the mediation. Although the mediators in this study were well informed on different approaches to involving children, disconcertingly few even mentioned it. This result is in accordance with the findings from another Norwegian mediation study (Ådanes, Haugen, Jensberg, Lossius, Husum, \& Rantalaiho 2011). One of the most potent sources of conflict in our material was in situations where older children initiated changes to or protested against long-standing care arrangements. These children were not only exposed to conflict but can also be understood as actors in the same field. Nevertheless, remarkably few participated in mediation sessions, even if the mediators sometimes seemed to see the potential value of this participation:

T: In the first round, usually we don't involve the child until we know that the parents actually agree on how this is done, share the intention of doing this and (agree about) how to deal with what she (the child) says. So we sort out in which cases (we do this), ...but we do involve both children and adolescents...too. 
RUNNING HEAD: Mediation strategies in the face of custody conflicts

This statement was potentially an invitation to involve the child but, as such, a hesitant and vague one. The mediator did not take an active and leading role in making this suggestion. As a general trend, parents were reluctant to involve children in the mediation. There might be several reasons for this reluctance. The parents could be concerned about the child siding with the other parent, imposing an extra burden on the already burdened child or fear that the child might reject and react negatively to such an invitation. In a different case, the mediator was more directive:

\section{T: There are different directions we can take from here. We could involve Sarah. I do} sometimes talk to children as a part of the mediation process. One way of doing this is that you help me phrase some questions for her. She'll get information about the opportunity to talk to me, that she can choose not to answer any of my questions in this, and that I will take down notes for a verbal report back to you. She will approve the report before I bring her reflections back to you. And then Mom and Dad make their decisions...

The cases in this study in which children took part were conducted as described in the example above. The parents formed the questions with the mediator, who highlighted this process as an opportunity to hear out the child as a basis for the parents to make their decisions. The child was thoroughly informed about the intention of the conversation and the opportunity to decline certain questions. In cases of high levels of conflict, it seemed all the more important to talk things through thoroughly. The child is usually the first to pick up on a disagreement or one parent's skepticism to such an idea, which usually hampers any attempt at such a conversation. 
RUNNING HEAD: Mediation strategies in the face of custody conflicts

Children are only one of several actors outside the mediation room that might be involved in the process. Other "external" actors influencing the process could be grandparents, counselors and lawyers. In some cases, these actors would be very present in the mediation room, in the form of being referred to as witnesses of the truth of one parent's argument. Parents would at times argue as if they themselves were not in charge of what they could accept and not. These circumstances hindered the mediation process and posed a challenge for the mediator, because she was left mediating with people who were not actually in the room. In some instances, the mediator would do chair-work and role-play interviews with the external influencing actor. Another alternative would be inviting these actors to a conversation or asking the parents' permission to call them. These approaches were not undertaken in any of the cases in this material.

\section{Conscious navigation along the identified dimensions}

We have described different approaches mediators take when dealing with separating parents experiencing a high level of conflict. These approaches can be understood in light of where focus is placed along the dimensions described above. This choice of focus seemed to affect whether the mediation continued or not. In many of the cases where the mediation was given more time, the parents ended up reaching an agreement. Thus, it seems reasonable to say that mediators working within the framework of the Norwegian mediation arrangements can help high-conflict parents reach an agreement if they place focus on the right side of these dimensions. This statement seems especially true for the first sessions. It is important, however, to emphasize that these dimensions are meant to show the range of opportunities the mediators have within this framework. It is not a question of either-or but one of making use 
RUNNING HEAD: Mediation strategies in the face of custody conflicts

of several strategies at different points along these dimensions, such as taking time to validate each parent's perspective and focusing on the details of an agreement.

It is worth noting that the examples shown and the points made in this article are based on the premise of the parents' competence and ability to care for their children. This approach involves the mediators' acceptance and understanding of the stressed situation in which the parents find themselves and the short-lived but unfortunate ways of reacting that this situation might provoke. This approach also involves the mediator accepting shared care arrangements that the parents agree upon even when they are not in accordance with the mediator's values. There are, however, cases where the parents' competence or abilities to care for the child are compromised to an extent that borders on abuse or neglect. In cases where the mediator suspects or is concerned about this possibility, she steps out of her role as a mediator. Such cases are not discussed in this article.

\section{Some central strategies in the face of custody conflicts}

A prerequisite for the approaches described above is that the mediator make all her resources and competence available to help the parents arrive at and own their solutions. Psychotherapy research highlights the importance of a good working alliance and describes some key ideas that seem to facilitate this process (Duncan, Miller, \& Wampold 2010; Lambert \& Barley 2002; Martin, Garske, \& Davis 2000). This study clearly supports similar ideas to be brought into the work with parents in conflict. We will briefly point out those approaches that stand out as especially important in this respect.

\section{Encourage hope}


RUNNING HEAD: Mediation strategies in the face of custody conflicts

One of a mediator's most important tasks is to find and encourage any little glimpse of hope that the parents might have for working better together. This task is evident in some of the examples given above: the mediator focuses on any points on which the parents do reach an agreement and shows them that they are heading somewhere by documenting in writing any progress they make. Parents who come to mediation often do so having given up on finding a solution for working together regarding childcare. They bring resignation, sadness, frustration and concerns into the mediation room. In facing this situation, it seems crucial that the mediator be ready to carry the hope for them for a while. One could say that the mediator has a special responsibility for the task of searching for points of light in the gloom. If she loses her faith in the process, it is likely to stall.

\section{$\underline{\text { Recognize both parents }}$}

To get anywhere in mediation, one has to start where the parents are. This involves providing space for each parent to address their concerns and to validate their experiences and thoughts. We have provided examples of mediators addressing each parent in turn and as individuals - because the parents themselves rarely experience their situation as a "we". The mediator focuses the beginning of the mediation on structuring the conversation into a form where both parents get space to express their perspective uninterrupted and the other is required to listen. As soon as this structure of turn-taking is established as an implicit norm, the mediator has more room to explore, sum up and validate each parent's experience in more detail. To achieve this process, the mediator must be able to tolerate emotional intensity, attacks and despair and withhold her inclination to "repair" the dialogue.

\section{$\underline{\text { Validate and accept differences }}$}


RUNNING HEAD: Mediation strategies in the face of custody conflicts

There is a risk of stalling the process if one is eager to build bridges too soon. We have described mediators who spend time on emphasizing and clarifying differences and points of disagreement between the parents. It might seem paradoxical to focus on these disagreements rather than on similarities. Nevertheless, in these cases, we have often observed parents reacting with an increased and often deadlocked focus on their dissimilarities if the mediator has focused on the opposite too soon. It is almost as if the parents experienced this focus as not being heard. Even in the face of authoritative language like "I demand that...", we have seen mediators finding opportunities to validate this sentiment while rephrasing it to a desire rather than demand ("You wish to...").

\section{$\underline{\text { Differentiate and choose topics }}$}

To set a common goal for the mediation process, the mediator must first ensure that both parents feel seen and heard and that they both trust that their perspective will be respected. From this beginning, the mediator can start actively differentiating topics to be addressed, be they about the agreement or about sources of conflict. With conflict, the different topics and emotional reactions are often so tangled up to start with that the dialogue easily descends into chaos. Although separating each topic from its context is a simplification, it seems a necessary step in the process of mediation. We have given several examples of how mediators placed focus on this process and, with time, helped the parents make a plan for which topics they wanted to address.

$\underline{\text { Identify and talk about relational topics, while holding on to agreement as a goal }}$

The conflict often stems from issues related to the break up or to concerns for the children. It is essential that the mediator take time to address these issues. There are several examples in our material of cases where relational topics were not addressed and later 
RUNNING HEAD: Mediation strategies in the face of custody conflicts

resurfaced to hinder the process. Inviting the parties to share their thoughts about these issues, especially in the first part of the process, seemed to ease the process of reaching an agreement. An important element in this approach seemed to be the mediators' ability to keep the attention on these conflict-driving topics without losing sight of the agreement about the children's daily care. The findings here are in accordance with some of those highlighted by Baitar, De Mol and Roper (2016).

\section{$\underline{\text { Put the pieces together }}$}

We have shown how written memoranda can be of help in separating topics and clarifying different solutions that the parents considered. When this strategy is combined with sufficient time to test the ideas in practice, it can contribute to forming an agreement. The most crucial task for the mediator here is to maintain a constructive structure in the dialogue, leaving the responsibility for the decisions to the parents. When the mediator uses her expert position to define what is best for the child, she risks being experienced as siding with one of the parents or as patronizing them. There is an immense difference between using one's expert knowledge to evaluate the parents' ideas and using it to explore them together. The latter certainly seems preferable, both because it avoids undermining the parents' own expert knowledge about their specific situation and because it encourages the parents' ownership of the process. This emotional support can in turn make parents more committed to the decisions they make.

\section{$\underline{\text { Hold on to the process while testing solutions }}$}

Finally, it is important to keep the dialogue going. However deadlocked or antagonistic the situation might seem, time tends to work for parents. It provides an opportunity to digest what has been said and make new observations and reflections between 
RUNNING HEAD: Mediation strategies in the face of custody conflicts

the sessions. Glimpses of light that were occluded in the first session might be easier to spot with time. Knowing this can help encourage the mediator to stay in the process.

\section{Closing remarks}

We have pointed to some ideas about the navigation in the troubled waters after a break-up between parents. Based on this study, our general advice to mediators working with high-conflict cases is to move gently to the right on the dimensions we have described, especially when the tension is high between the parties. Otherwise, in order to increase the likelihood that the mediation process continues, it seems sensible to address the parents in flexible, respectful and confirming ways.

This study does not document that a successful mediation process will ensure that the parents manage to cooperate afterwards in the best interest of their children. We need more naturalistic studies that close the gaps between what happens in the mediation process, where the parties are at the end of it and how they collaborate afterwards.

\section{References}

Baitar, R., De Mol, J., \& Rober, P. (2016). Exploring helpful tensions between divorce mediators and clients: A relational dialectic analysis. Conflict Resolution Quarterly, 34, 7-29.

Brown, E. M. (1997). Comprehensive divorce mediation. I: E. Kruk (Ed.), Mediation and conflict resolution in social work and human services (pp. 37-54). Chicago: Nelson-Hall.

Buch, R.A.B., \& Folger, J. P. (1994). The promise of mediation: Responding to conflict through empowerment and recognition. San Francisco: Jossey-Bass.

Charmaz, K. (2008). Grounded theory. In J. A. Smith (Ed.), Qualitative psychology. A practical guide to research methods (pp. 81-110). Los Angeles: Sage. 
RUNNING HEAD: Mediation strategies in the face of custody conflicts

Coogler, O. J. (1978). Structured mediation in divorce settlement: A handbook for marital mediators. Lexington, M. A.: Lexington.

Duncan, B. L., Miller, S. D., Wampold, B. E. \& Hubble, M. A. (Eds.) (2010). The heart and soul of change: Delivering what works in therapy. Washington, DC, US: American Psychological Association.

Emery, R. E. (2012). Renegotiating family relationships. Second Edition. New York: Guilford Press.

Emery, R. E., \& Sbarra, D. (2005). The emotional sequelae of nonmarital relationship dissolution: Analysis of change and intraindividual variability over time. Personal Relationships, 12, 213-232.

Gulbrandsen, W. (2015). En studie av meklingsstrategier i møte med det konfliktfylte [A study of mediation strategies in high conflict sessions]. Tidsskrift for Norsk Psykologforening, 52, 95-106.

Gulbrandsen, W., Haavind, H., \& Tjersland, O. A. (2018). High-conflict parents in mediation: An analysis of dialogues and sources to conflict. Conflict Resolution Quarterly, 35, 335-339.

Haynes, J. M. (1981). Divorce mediation: A practical guide for therapists and counsellors. New York: Springer.

Irving, H. H., \& Benjamin, M. (2002). Therapeutic family mediation: Helping families resolve conflict. Thousand Oaks, C: Sage.

Kruk, E. (Ed.) (1997). Mediation and conflict resolution in social work and the human services. Chicago: Nelson-Hall.

Kjøs, P., Tjersland, O.A. \& Roen, K. (2015). The mediation window: Regulation of argumentation and affect in custody mediation, Journal of Divorce \& Remarriage, 55, 527538. 
RUNNING HEAD: Mediation strategies in the face of custody conflicts

Lambert, M. J., \& Barley, D. E. (2002). Research summary on the therapeutic relationship and psychotherapy outcome. In J. C. Norcross (Ed.), Psychotherapy relationships that work: Counselor contributions and responsiveness to patients (pp. 17-32). New York: Oxford University Press.

Lang, M., \& Taylor, A. (2000). The making of a mediator: developing artistry in practice. San Francisco: Jossey-Bass.

Lov om ekteskap, 1991, 07-04. No.47. [Act on Marriage].

Martin, D. J., Garske, J. P., \& Davis, M. K. (2000). Relation of the therapeutic alliance with outcome and other variables: a meta-analytic review. Journal of Consulting and Clinical Psychology, 68, 438-50.

Poitras, J., \& Raines, S. (2013). Expert mediators. Overcoming mediation challenges in workplace, family, and community conflicts. Lanham: Jason Aronson.

Saposnek, D. T. (2004). Commentary: The future of the history of family mediation research. Conflict Resolution Quarterly, 22, 37-53.

Slaikeu, K. (1996). Push comes to shove: A practical guide to mediating disputes. San Francisco: Jossey-Bass.

Tjersland, O.A. (1998). Strategies in mediation explored and developed during a research project. Mediation Quarterly, 15, 105-117.

Tjersland, O. A., \& Gulbrandsen, W. (2010). Mekling ved samlivsbrudd: modeller og ideologi [Divorce mediation: Models and ideology]. Tidsskrift for Norsk Psykologforening, 47, 692-700.

Tjersland, O. A., Gulbrandsen, W., \& Haavind, H. (2015). Mandatory mediation outside the court: Does it works satisfactory with parents in high conflicts? Conflict Resolution Quarterly, 33, 19-34. 
RUNNING HEAD: Mediation strategies in the face of custody conflicts

Walker, J., McCarthy, P., \& Timms, N. (1994). Mediation: The making and remaking of cooperative relationships: an evaluation of the effectiveness of comprehensive mediation. Newcastle: Relate Centre for Family Studies, Newcastle University.

Winslade, J., \& Monk, G. (2001). Narrative mediation. A new approach to conflict resolution. San Francisco: Jossey-Bass.

Ådanes, M., Haugen, G. M. D., Jensberg, H., Lossius Husum, T. \& Rantalaiho, M. (2011). Hva karakteriserer vanskelige saker i foreldremekling, og er meklingsordningen godt nok tilpasset? Resultater fra evaluering av mekling etter ekteskapslov og barnelov. Fokus på Familien, 2, 86-115. 